\title{
Study on Analog Theory of Rock Mass Simulation and Its Engineering Application
}

\author{
Sun Shaorui, Lu Yexu, Xu Yuanyuan, Liu Jin, and Wei Jihong \\ College of Earth Science and Engineering, Hohai University, Nanjing 210098, China \\ Correspondence should be addressed to Sun Shaorui; ssrfish@hhu.edu.cn
}

Received 3 May 2013; Revised 24 August 2013; Accepted 10 October 2013

Academic Editor: Stephane P. A. Bordas

Copyright ( 2013 Sun Shaorui et al. This is an open access article distributed under the Creative Commons Attribution License, which permits unrestricted use, distribution, and reproduction in any medium, provided the original work is properly cited.

\begin{abstract}
During construction of 3D geological models, it is difficult to determine the uniform between geological model and true model. As a comprehensive index, rock quality designation (RQD) is reliable to assess the rationality of geological models. Unfortunately, The RQD of rockmass is determined completely by the deterministic threshold value and directions of the scan lines presently. To avoid this drawback, the modified method of the RQD value based on the threshold value and 3D space is proposed in this paper. Simultaneously, the analogue-simulation method based on rupture mechanism and classification of discontinuities is proposed. The elliptical discontinuity is considered for general discontinuity, and the special discontinuities, such as bedding, fault, and interlayer are dealt with individually. The accuracy of the 3D model is verified by the modified RQD. The 3D model of the rockmass is analogue simulated through repetitively obtaining data from the interval confidence of geometrical parameters of discontinuities, which are determined by a mass of data derived from field investigation. Besides, the dam base of the Xiangjiaba hydropower station is taken as an example, and the 3D model of the dam base is analog-simulated; its stability is evaluated by DDA method. The safety coefficient of the dam base is obtained by utilizing the overload method.
\end{abstract}

\section{Introduction}

At present, 3D geological simulation methods have been developed from model construction to practical computation $[1,2]$. 3D geological models have been easily accepted as efficient methods to understand the engineering characteristics of rock masses, as these models are constructed with discontinuities and structural bodies as 3D networks. The discreteelement method (DEM), which was firstly developed by Cundall, has been widely used to construct $3 \mathrm{D}$ geological models in rock engineering applications. Jing [3] has introduced additional aspects of the DEM in different related engineering problems. Andersson and Dverstorp [4], Elsworth [5], Long et al. [6], and Smith and Schwartz [7] have also widely used the discrete fracture network (DFN) to research the behavior of rock masses. Although these software programs have been successfully used to simulate the behavior of rock fractured systems, the aforementioned research methods and their application to engineering problems are still limited to simplify the representations of the critical discontinuities of rock masses. In addition, the uniformity between constructed and true models lacks the validation methods, which will cause the constructed model to be unreliable. For some particular types of discontinuities, such as fault, fracture zone, and interlayer, there is no way to realize in these methods. Therefore, 3D geological simulation method in this study can overcome these drawbacks through analogue simulation technique considering particular discontinuities.

Rock quality designation (RQD) has been widely used to classify the discontinuity of rock masses and assess the intactness of rock masses. In previous studies, the applications of RQD have been mainly based on a deterministic threshold value and a single scanline direction. Priest and Hudson [8] have studied RQD and proposed a relationship between the fracture frequency and RQD. Harrison [9] has presented equations derived by analyzing fracture frequencies with different distributions, which may expand the range of RQD values. Sen and Kazi [10] and Şen [11] have studied RQD along a scanline with any specific orientation and established a relationship between the RQD value and fracture frequency along the chosen orientation. Zhang and Einstein [12], Jiang et al. [13], and Milne et al. [14] have studied the relationships 
between RQD and rock mass parameters, such as fracture frequency, deformation modulus, volumetric joint count, and permeability coefficient. Snow [15] has pointed out that RQD and fracture frequency decrease with depth increasing. However, after many years of research, RQD has gradually come to favor the methods of quantitative and multiple indexes, and it has become more and more widely known that rock structure has a great influence on rock quality. Because of anisotropy and nonhomogeneity of rockmass, the previous evaluation methods of the RQD have some drawbacks, such as deterministic threshold value and scanline. The new method in this paper considers the different threshold values and measure methods from the angle of full space. The general RQD proposed in this paper evaluates rock mass quality based on many RQD balls with the different measure threshold values. Therefore, the general RQD is adopted to overcome the drawbacks of traditional evaluation method of the RQD.

The discontinuous deformation analysis (DDA) method has been widely used to assess the stability of rock mass engineering. The method has been developed for 2D problems by Shi and Goodman [16] and expanded to 3D by Shi [17] and Jiang and Yeung [18]. Some researchers, such as Yeung et al. [19], Hatzor and Feintuch [20], MacLaughlin and Berger [21], Doolin and Sitar [22], and Tsesarsky et al. [23], have confirmed the verification and validation of DDA by comparing the predictions from the method with analytical solutions, as well as with other numerical methods and laboratory and field measurements. In addition, DDA can also be viewed as a mature and reliable method to apply in the stability analysis of rock engineering; for example, Hatzor et al. [24] and Sitar et al. [25] have used DDA to investigate slope stability, and Kim et al. [26], Wu et al. [27], and Tsesarsky and Hatzor [28] have used it to analyze tunneling stability in discontinuous rock masses. In the past study on DDA method, the orientation of discontinuity is constant when DDA method is used to conduct numerical simulation. It is unreasonable for the true geometrical characteristics of natural discontinuity. Meanwhile, variable orientation of discontinuity can produce many polyhedrons with different shape compared with that of constant orientation. Additionally, another problem for the DDA method is that the particular discontinuities cannot be considered. Therefore, in order to avoid two drawbacks, both the particular types of discontinuities by improving preprocess program and the variable orientation of natural discontinuity are considered for the simulation method in this study.

At present, a wide variety of rock quality assessment methods have taken rock structure into account; however, it is necessary to determine how to adapt the rock structure model into the adaptive mechanical model for providing the basic data for model experiments and rock masses intactness assessment. The 3D structure model of rock masses is typically acquired by using discontinuities and spacing, block size, and other rock intactness indexes. There are three issues involved in the acquaintance of rock structure: (i) how to gain the reasonable values for the geometrical characteristics of the discontinuities. It remains open to discuss how to describe the whole rock masses through the representative data from field measurements, when simulating the space geometry of discontinuities, and the effects of the geometrical characteristics of the rock are partially caused by tectonic movement and so forth. The second issue is (ii) how to reasonably understand the rock masses formed by discontinuities. Rock masses are the combination of discontinuities and structural body. Under the condition that the geometrical characteristics of the rock masses have been confirmed, it is worth considering how to simulate the rock masses using these characteristics and how to compare the simulated rock masses with the virtual ones. Furthermore, there are several different beliefs concerning how to define the index reflecting the intactness of rock masses. (iii) How to build the connection between the numerical computational and the geological models constructed using the 3D network simulation method is the third one. Currently, most numerical computational methods which take rock as a continuous medium are not effective in distinguishing the characteristics of rock masses. Even if the discontinuous analysis method is adopted in some cases, the general means will not compensate for the deficiencies in the numerical calculation of engineering; thus it is necessary to establish the relationships between the 3D geological models and discontinuous deformation analysis methods.

\section{Basic Principles and Methodologies}

2.1. Simulation Method of Discontinuities. Despite the fact that the technique of discontinuous network simulation (DNS) has been greatly improved in recent years, this method is not particularly accurate, due to its hypothesis. It assumes that the spatial shape of the discontinuities is circular, while this is not necessarily true. In addition, the technique of the DNS ignores the effects of the large-scale discontinuities, taking only the grade IV and V discontinuities into account. It is easy to understand that the application and decision of the 3D simulation technique are restricted, and, as matter of a fact, the grade IV and V discontinuities are the ones which play controlling roles in the local stabilization of rock masses. In this paper, the large-scale discontinuities are firstly considered during the construction of the 3D geological model. The production of the grade IV and V discontinuities is based on the 3D model, including the large scale discontinuities such as fault and weak interlayers. Through a large amount of the field observations and research regarding the shape of the discontinuities, it is believed that the discontinuities should not be categorized into a single circular shape, due to the fact that the production of the discontinuities is affected mainly by the tectonic movement. As known, the stress ellipsoid is applied to structure geology for explaining rock failure and deformation of rock masses based on the definition of mathematics and the physical meaning. Therefore, the shape of discontinuities directly affected by tectonic stress should not be circular in shape, but elliptical, generally due to the unequality of the values of the maximum and minimum principal stresses. Based on this view, the elliptical shape would be adopted to corresponding discontinuities affected by tectonic stress, and the steps of the DNS are as follows: (i) take samples of the discontinuities through field measurements; 


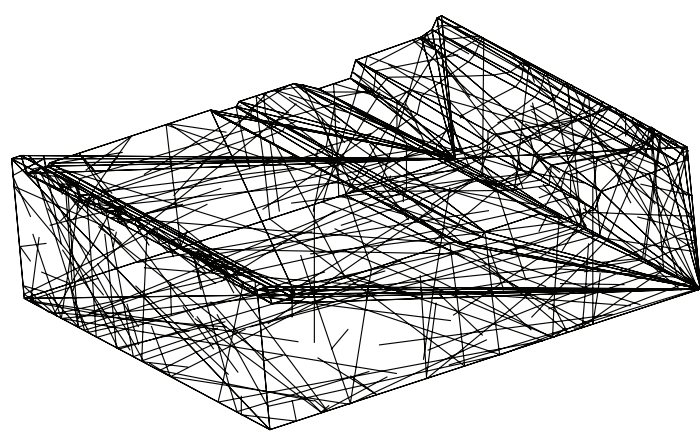

(a) Discontinuities

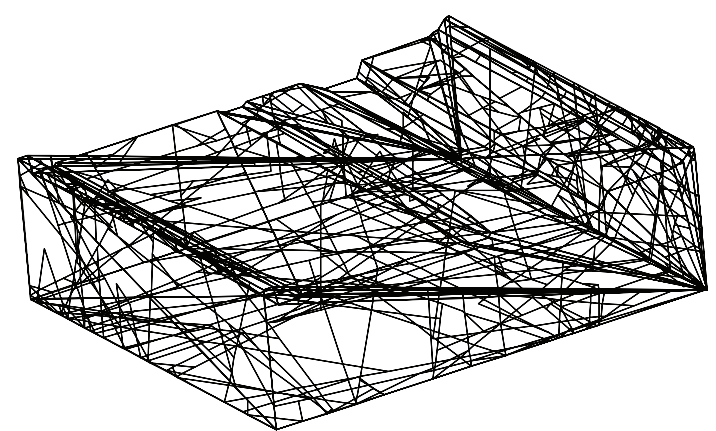

(b) Structural bodies

Figure 1: Map of the DNS for the Xiangjiaba hydropower station dam base.

(ii) create probabilistic models of geometrical parameters of the discontinuities such as orientation, spacing, and trace length; (iii) make use of the Monte-Carlo random simulation technique to obtain random data from the confidence interval of geometrical parameters of discontinuities; (iv) construct the large-scale discontinuities in the 3D model, such as the fault, bedding, and interlayer; (v) construct the grade IV and $\mathrm{V}$ discontinuities in the 3D model; and (vi) create a complete network map of the DNS and form its boundaries. The boundaries formed by the discontinuities are shown in Figure 1(a), while Figure 1(b) shows the boundaries of the dam base formed by the structural bodies.

\subsection{Verification of the DNS}

2.2.1. RQD and Its Deficiencies. Rock masses are discontinuous, inhomogeneous, and anisotropic in terms of their discontinuous geometry; thus it is a difficult task to simulate the whole characteristics of rock masses. At present, ROD, a method used to evaluate the intactness and quality of rock masses, is the main means of simulating the discontinued properties of rock. The intactness coefficient of rock masses deals with the anisotropic property from the whole rock mass. However, RQD makes an objective appraisal of the intactness of the rock mass using the scanlines, such as borehole, tunnel, and field outcrop. The advantages and disadvantages of the method are described as follows.

(i) It is not proper to use the RQD method to merely evaluate the quality of rock mass through a borehole which narrowly shows the condition of rock masses, because the rock mass has the property of anisotropy. In addition, the RQD method proposed by DEER in 1964 gave the deterministic value of $10 \mathrm{~cm}$, which is defective at measuring the intactness of rock masses, and increases the amount of calculation if it is used to evaluate the stability of the rock mass, due to the production of a mass of structural elements separated by discontinuities. For example, the actual direction of a scanline in the project is often vertical in the borehole and horizontal in the tunnel, and the RQD value of single direction scanline cannot reflect the intact degree of the rock masses quality if considering the anisotropy of the rock masses. In addition, a threshold value of $10 \mathrm{~cm}$ is nevertheless an arbitrarily selected value. Therefore, if the variable threshold can have a dramatic effect on the computed RQD, it is appropriate that the assessment of the RQD can be further investigated in order to determine a method for selecting the threshold value, rather than always relying on the customary value. In order to avoid these dimensional effects, another threshold value should be adopted according to the specific engineering project.

(ii) The rock masses are constituted by blocks of different sizes and shapes, which are formed by the separation of the discontinuities. When analyzing the stability of the rock masses in the project using the DDA method, every structural element will be formed by a closed loop constituted by several traces, and the traces which do not constitute a closed loop will be deleted or trimmed. Therefore, the RQD values are not reasonable due to the different quantity traces in the measure scanlines intersecting with the redundant traces, and thus both should be taken into account during the analysis of RQD. The dam base model formed by structural elements should be reliable from the perspectives of theory and field investigation.

2.2.2. Modified Approach of RQD Evaluation. Two main approaches for RQD evaluation are proposed as follows. (1) Improve the gauge of threshold value. In order to conveniently calculate using the DDA method and satisfy the reasonable threshold value of the rock mass intactness, ten gauges of threshold values, spaced every $1.0 \mathrm{~m}$, from $1.0 \mathrm{~m}$ to $10.0 \mathrm{~m}$, are used to evaluate the intactness of the rock masses, thus creating a combination of the intactness and measurement indexes. (2) Change the single direction to 3D space. Based on the perspective of rock mass anisotropy, an all-sided gauge of the threshold value is adopted to measure the RQD in 3D space rather than in the vertical or horizontal direction.

Four RQD balls formed in four different threshold values are shown in Figure 2. As seen, the shape of the RQD ball is circular when the threshold value is smaller, and the characteristic of the rock mass approaches isotropy; on the contrary, the larger the threshold value is, the more 

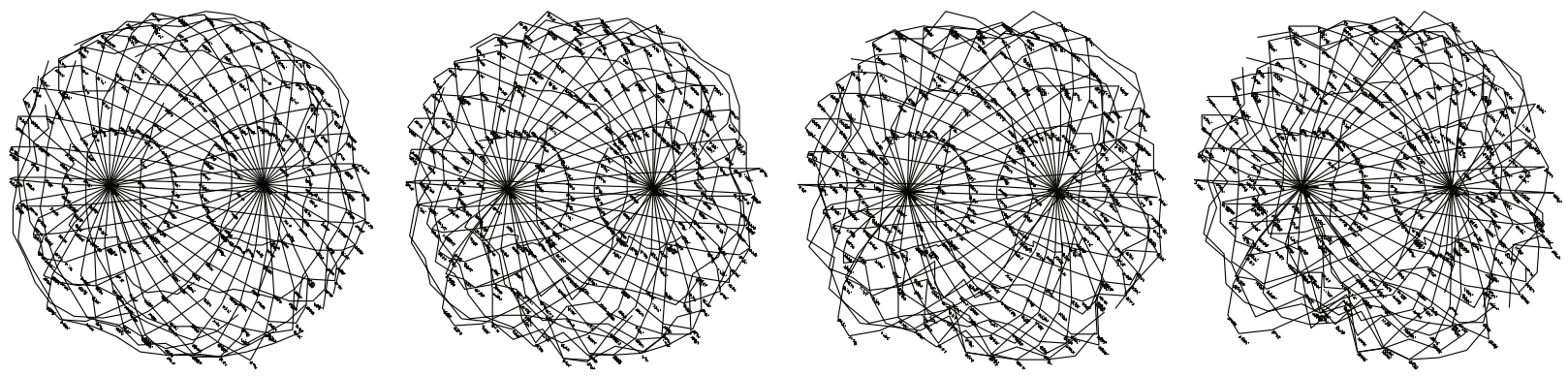

FIgURE 2: 3D RQD of the Xiangjiaba hydropower station dam base rock masses.

disproportionate the shape is, and the rock mass anisotropy may be clearly seen. These results show that the RQD ball is indeed capable of representing the characteristics of rock mass structures.

2.2.3. RQD Verification Methods. In order to verify the reasonability of $3 \mathrm{D}$ geological model of DNS, the actual measured RQD is compared with the simulated one. The steps of the measurement method are as follows.

(i) Calibration of the borehole: according to the simulated rock masses, the RQD of the rock masses in the actual position of the drill hole is evaluated, and the results with those of the actual measurements are compared. The error between the actual measured values and the simulated values of the geometrical parameters must not be avoided. RQD is used to calibrate the simulated model by adjusting the geometrical parameters of the discontinuities, because RQD is a comprehensive index, which contains the geometrical characteristics of discontinuities, such as orientation, spacing, and trace length, to reflect the intactness of rock masses. Therefore, it is necessary to verify the RQD by adjusting the geometrical characteristic of the discontinuities until the results satisfy the demands.

(ii) Calibration of the block characteristic of the rock masses: contrast the size and magnitude of the block formed from the 3D model with those of the actual field investigation. The span of the block may be satisfied by adjusting the geometrical parameters of the discontinuities.

It is believed to be very difficult to simultaneously satisfy the two aforementioned aspects. In general, the first one aspect is fulfilled, and then the other assessment aspect is calibrated accordingly.

2.3. Basic Theory of Discontinuous Deformation Analysis (DDA). Recently, the basic theory of DDA begins to reach maturity in correlative research and has made significant development in engineering application. The key contents of DDA are discussed below. Blocks in DDA are connective and form a block system by the contact constraint between two

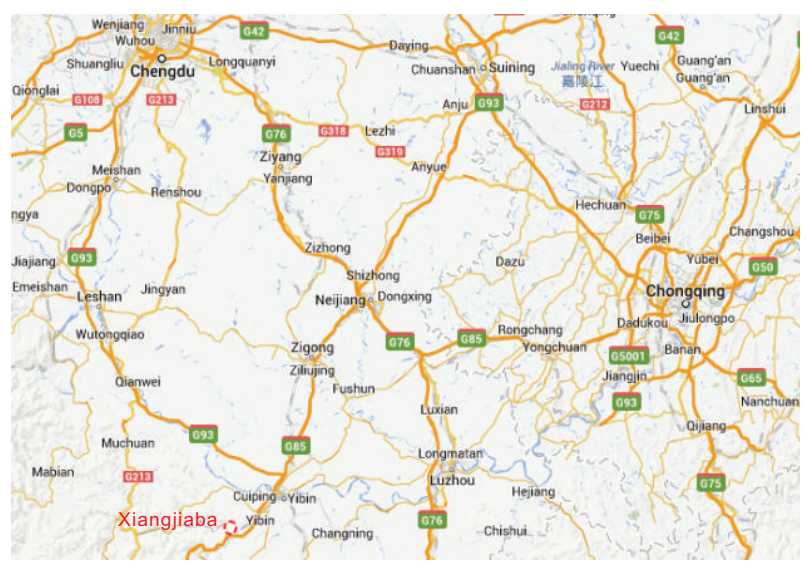

FIgURE 3: Location of dam base zone.

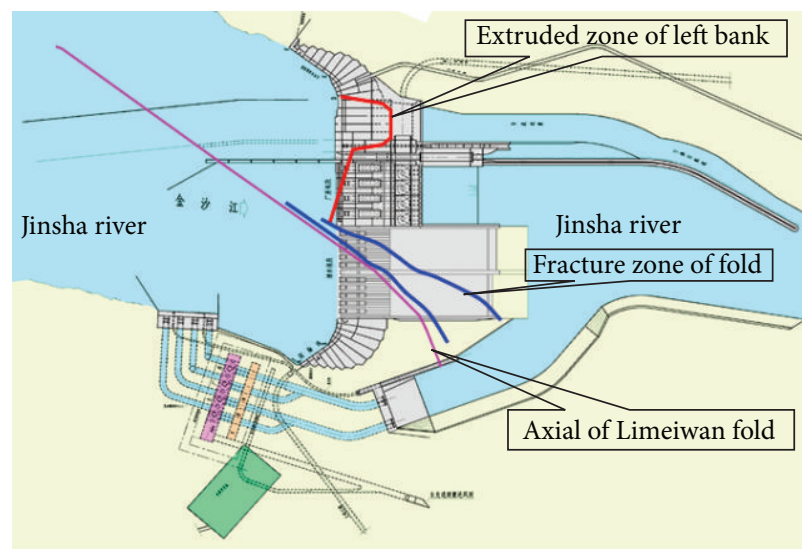

FIgURE 4: Layout of dam base zone.

blocks. Within representing the number of blocks in the block system, the following equations are listed together in

$$
\left(\begin{array}{ccccc}
K_{11} & K_{12} & K_{13} & \cdots & K_{1 n} \\
K_{21} & K_{22} & K_{23} & \cdots & K_{2 n} \\
K_{31} & K_{32} & K_{33} & \cdots & K_{3 n} \\
\vdots & \vdots & \vdots & \ddots & \vdots \\
K_{n 1} & K_{n 2} & K_{n 3} & \cdots & K_{n n}
\end{array}\right)\left(\begin{array}{c}
D_{1} \\
D_{2} \\
D_{3} \\
\vdots \\
D_{n}
\end{array}\right)=\left(\begin{array}{c}
F_{1} \\
F_{2} \\
F_{3} \\
\vdots \\
F_{n}
\end{array}\right)
$$

Every block possesses six degrees of freedom. Each element $\left[K_{i j}\right]$ given in the coefficient matrix in (1) is a $6 \times 6$ 
TABLE 1: Statistical results of geometrical parameters of discontinuities.

\begin{tabular}{|c|c|c|c|c|c|c|c|}
\hline \multirow{2}{*}{ No. } & \multicolumn{2}{|c|}{ Orientation } & \multirow{2}{*}{ Statistical indexes } & \multirow{2}{*}{ Model } & \multirow{2}{*}{ Mean } & \multirow{2}{*}{ Standard variation } & \multirow{2}{*}{ Samples } \\
\hline & $\mathrm{Dip} /{ }^{\circ}$ & Dip angle ${ }^{\circ}$ & & & & & \\
\hline \multirow{4}{*}{ (1) } & \multirow{4}{*}{$45.54 \sim 115.54$} & \multirow{4}{*}{$8.46 \sim 58.46$} & Spacing/m & Log-normal & 0.60 & 0.79 & 360 \\
\hline & & & $\mathrm{Dip} /{ }^{\circ}$ & Normal & 85.24 & 13.32 & 374 \\
\hline & & & Dip angle $/^{\circ}$ & Uniform & 36.77 & 11.44 & 374 \\
\hline & & & Trace length/m & Log-normal & 23.80 & 19.76 & 374 \\
\hline \multirow{4}{*}{ (2) } & \multirow{4}{*}{ 170.0 190.0 } & \multirow{4}{*}{$64.61 \sim 89.61$} & Spacing/m & Log-normal & 11.10 & 32.64 & 23 \\
\hline & & & $\mathrm{Dip} /{ }^{\circ}$ & Normal & 181.46 & 6.33 & 28 \\
\hline & & & Dip angle $/^{\circ}$ & Normal & 81.21 & 7.17 & 28 \\
\hline & & & Trace length/m & Uniform & 2.01 & 0.34 & 28 \\
\hline \multirow{4}{*}{ (3) } & \multirow{4}{*}{$326.57 \sim 360.00$} & \multirow{4}{*}{$41.47 \sim 76.47$} & Spacing/m & Log-normal & 5.29 & 24.44 & 49 \\
\hline & & & $\mathrm{Dip} /{ }^{\circ}$ & Uniform & 345.84 & 8.84 & 58 \\
\hline & & & Dip angle $/^{\circ}$ & Uniform & 60.22 & 8.56 & 58 \\
\hline & & & Trace length/m & Log-normal & 2.07 & 1.49 & 58 \\
\hline \multirow{4}{*}{ (4) } & \multirow{4}{*}{$262.01 \sim 327.01$} & \multirow{4}{*}{$24.81 \sim 69.81$} & Spacing/m & Log-normal & 3.50 & 12.64 & 54 \\
\hline & & & $\operatorname{Dip} /{ }^{\circ}$ & Uniform & 292.48 & 16.96 & 63 \\
\hline & & & Dip angle $/^{\circ}$ & Uniform & 43.47 & 6.07 & 63 \\
\hline & & & Trace length/m & Log-normal & 0.95 & 0.54 & 63 \\
\hline \multirow{4}{*}{ (5) } & \multirow{4}{*}{$44.74 \sim 74.74$} & \multirow{4}{*}{$58.30 \sim 88.30$} & Spacing/m & Log-normal & 2.20 & 7.66 & 22 \\
\hline & & & $\operatorname{Dip} /{ }^{\circ}$ & Normal & 60.44 & 7.95 & 27 \\
\hline & & & Dip angle $/^{\circ}$ & Log-normal & 69.33 & 9.83 & 27 \\
\hline & & & Trace length/m & Log-normal & 3.64 & 2.12 & 27 \\
\hline
\end{tabular}

TABLE 2: Physical-mechanical parameters of rock masses in the dam base.

\begin{tabular}{|c|c|c|c|c|c|}
\hline Materials & Density $/ \mathrm{kN} / \mathrm{m}^{3}$ & Modulus/GPa & Poisson's ratio & $f^{\prime}$ & $c^{\prime} / \mathrm{MPa}$ \\
\hline Concrete & 24.0 & 17.60 & 0.167 & & \\
\hline Bed rock (II) & 26.0 & 15.00 & 0.220 & 1.20 & 1.40 \\
\hline Bed rock $\left(\mathrm{III}_{1}\right)$ & 26.0 & 7.00 & 0.250 & 0.99 & 1.00 \\
\hline Bed rock $\left(\mathrm{III}_{2}\right)$ & 26.0 & 5.50 & 0.280 & 0.86 & 0.80 \\
\hline $\operatorname{Bed} \operatorname{rock}\left(\mathrm{III}_{2} \sim \mathrm{IV}\right)$ & 26.0 & 4.00 & 0.290 & 0.77 & 0.65 \\
\hline Soft layers $P_{n}$ & 20.0 & 0.75 & 0.400 & 0.35 & 0.10 \\
\hline
\end{tabular}

TABLE 3: Intactness assessment of rock masses of Xiangjiaba hydropower station dam base.

\begin{tabular}{|c|c|c|c|c|c|}
\hline \multirow{2}{*}{$\begin{array}{l}\text { Rock quality } \\
\text { grade }\end{array}$} & \multirow[t]{2}{*}{ Degree of weathering } & \multicolumn{3}{|c|}{ Intactness of rock masses } & \multirow{2}{*}{$\begin{array}{l}\text { Location of } \\
\text { distribution }\end{array}$} \\
\hline & & $\begin{array}{l}\text { Velocity of acoustic } \\
\text { wave } / \mathrm{m} / \mathrm{s}\end{array}$ & $\begin{array}{l}\text { RQD in the } \\
\text { tunnel/\% }\end{array}$ & $\begin{array}{l}\text { RQD in the } \\
\text { borehole/\% }\end{array}$ & \\
\hline I & Unweathered & $>5000$ & $>90$ & $>85$ & Depth of dam base \\
\hline II & $\begin{array}{l}\text { Unweathered to weak } \\
\text { weathering }\end{array}$ & $4000-5000$ & $75-90$ & $60-85$ & Zones 1, 2, 4 \\
\hline \multirow[t]{3}{*}{ III } & $\begin{array}{l}\text { Moderate weathering } \\
\text { (lower) to weak } \\
\text { weathering }\end{array}$ & $3500-4000$ & $62.5-75$ & $45-60$ & Zones $1,4,5,6$ \\
\hline & $\begin{array}{l}\text { Moderate weathering } \\
\text { (upper) }\end{array}$ & $3000-3500$ & $50-62.5$ & $30-45$ & Zone 6 \\
\hline & $\begin{array}{l}\text { Weak weathering to } \\
\text { unweathered }\end{array}$ & & & & Zone 3 \\
\hline \multirow[t]{2}{*}{ IV } & & $2000-3000$ & $25-50$ & $5-30$ & Zones 3, 5 \\
\hline & $\begin{array}{l}\text { Weak weathering to } \\
\text { unweathered }\end{array}$ & & & & $\begin{array}{l}\text { Influence band of } \\
\text { fault and } \\
\text { concentrated joint } \\
\text { band }\end{array}$ \\
\hline $\mathrm{V}$ & & $<2000$ & & & $\begin{array}{l}\text { Shattered fault zone } \\
\text { and weak interlayer }\end{array}$ \\
\hline
\end{tabular}

Notes: The zone of the dam base is divided by six sub-zones, which are arranged in order from the right bank to left bank of the Jinsha River. 


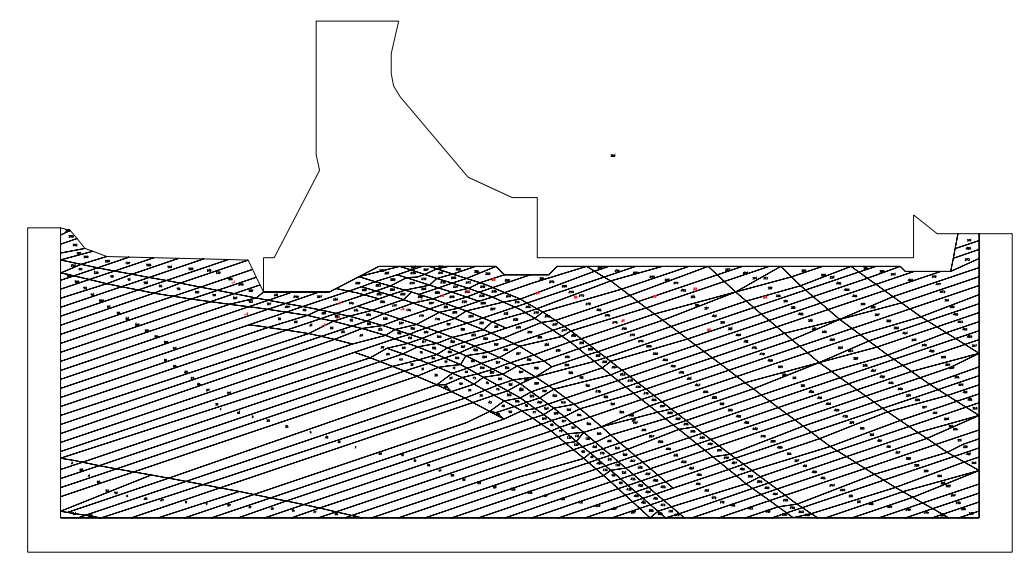

Figure 5: Computation model of dam base of Xiangjiaba hydropower station.

submatrix; $\left[D_{i}\right]$ and $\left[F_{i}\right]$ are $6 \times 1$ submatrices; $D_{i}$ represents the deformation variable of block $i$; and $F_{i}$ is the load which is placed on the six deformation variables of block $i$. The six variables of each block are listed in

$$
\left(u_{0}, v_{0}, r_{0}, \varepsilon_{x}, \varepsilon_{y}, \gamma_{x y}\right)
$$

where $\left(u_{0}, v_{0}\right)$ is the rigid body displacement of the special point $\left(x_{0}, y_{0}\right)$ in the block; angle $r_{0}$, shown with the radian, is an angle of rotation around the center point $\left(u_{0}, v_{0}\right)$ in the block; $\varepsilon_{x}, \varepsilon_{y}$ are the normal strain; and $\gamma_{x y}$ is the shear strain.

DDA is based on the principle of the minimum potential energy; the total potential energy $\Pi$ is the sum of all of the potential energy. Use the equation below to calculate each stress and force potential energy, as well as their respective differentials. The equation of the matrix $\left[K_{i j}\right]$ is shown in

$$
\frac{\partial^{2} \Pi}{\partial d_{r i} \partial d_{s i}}=0, \quad r, s=1, \ldots, 6 .
$$

All the terms in (3) form a $6 \times 6$ submatrix, which is the submatrix $\left[K_{i j}\right]$ in (1). It may be clearly seen that (3) and the coefficient matrix are symmetrical. The equation of the matrix $\left[F_{i}\right]$ is shown in

$$
-\frac{\partial \Pi(0)}{\partial d_{r i}}=0, \quad r=1, \ldots, 6 .
$$

All the terms of (4) form a $6 \times 6$ submatrix, which will be added into the submatrix $\left[F_{i}\right]$.

Many components of the total stiffness matrix are provided by the single block and block systems, including the elastic, initial stress, point load, volume force, inertia force, initial displacement, bolt connection, normal contact force, tangent contact force, and friction force submatrices. The role played by each part of the total stiffness matrix in every situation may be clarified, provided that the appropriate potential energy expression is performed for each situation, and (3) or (4) is used. The simulation process is realized by a modified source code, which is considered to be the influence of the weak interlayer, based on the original code programming described by Shi $[16,17]$.

\section{Case study}

3.1. Engineering Geology Survey. The Xiangjiaba hydropower station is the final planned stepped hydropower station along the Jinsha River (Figure 3 ). Figure 4 shows the dam base of the Xiangjiaba hydropower station. The engineering geological conditions of the dam site zone are very complex: the river bed contains 15 small faults, which may be divided into two groups; the first group discontinuity which its strike is NNW, contains seven faults with the orientation of $280 \sim$ $300^{\circ} / \mathrm{SW} \angle 70 \sim 80^{\circ}$; the other, strike NE, contains six faults with the orientation of $30^{\circ} \sim 50^{\circ} / \mathrm{NW} \angle 65^{\circ} \sim 80^{\circ}$.

In the dam site zone, the joint and fissure developments differ from each other due to their different tectonic locations. If the zone is divided based on tectonic location, the stratum steep-dip is located within the core of the fold. The right side of the bed and the right bank are both on the SW limbs of the fold, and the left side of the bed and the left bank are both on the NE limbs. The joint and fissure develop greatly, with the strikes of the superiority jointing groups being $40 \sim 70^{\circ}$ and $320 \sim 340^{\circ}$, the former of which are fissures with medium- to high-dip angles, and the latter are joints with low-dip angles. The density of the joint and fissure is $10-20$ per $\mathrm{m}$. The joints on the left bank develop better than those on the right bank; there are two superiority jointing groups on the left bank, which have strikes of $280 \sim 300^{\circ}$ and $60 \sim 80^{\circ}$ and the density is $2-5$ per $\mathrm{m}$; and there are two superiority joint groups in the right with strikes of $60 \sim 80^{\circ}$ and $280 \sim 300^{\circ}$ and the density is $1-3$ per $m$. The geometrical characteristics and corresponding probability distribution models of the main discontinuities are listed in Table 1.

3.2. Calculation Parameters and Analysis. The material parameters used for calculation in the DDA method are shown in Table 2.

\subsection{Analysis of the Calculation Results}

3.3.1. Computation Model. Figure 5 shows the section of the 3D geological model of the dam base which is constructed by the DNS techniques. It may be seen that the combination of 


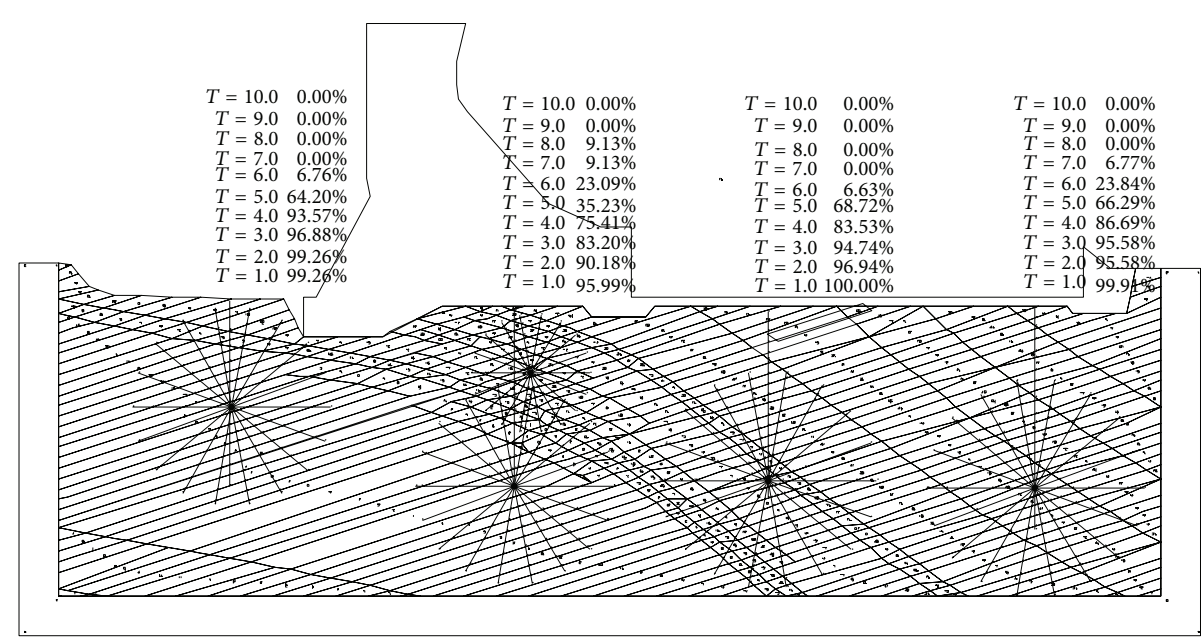

(a) Location and scale of RQD method application
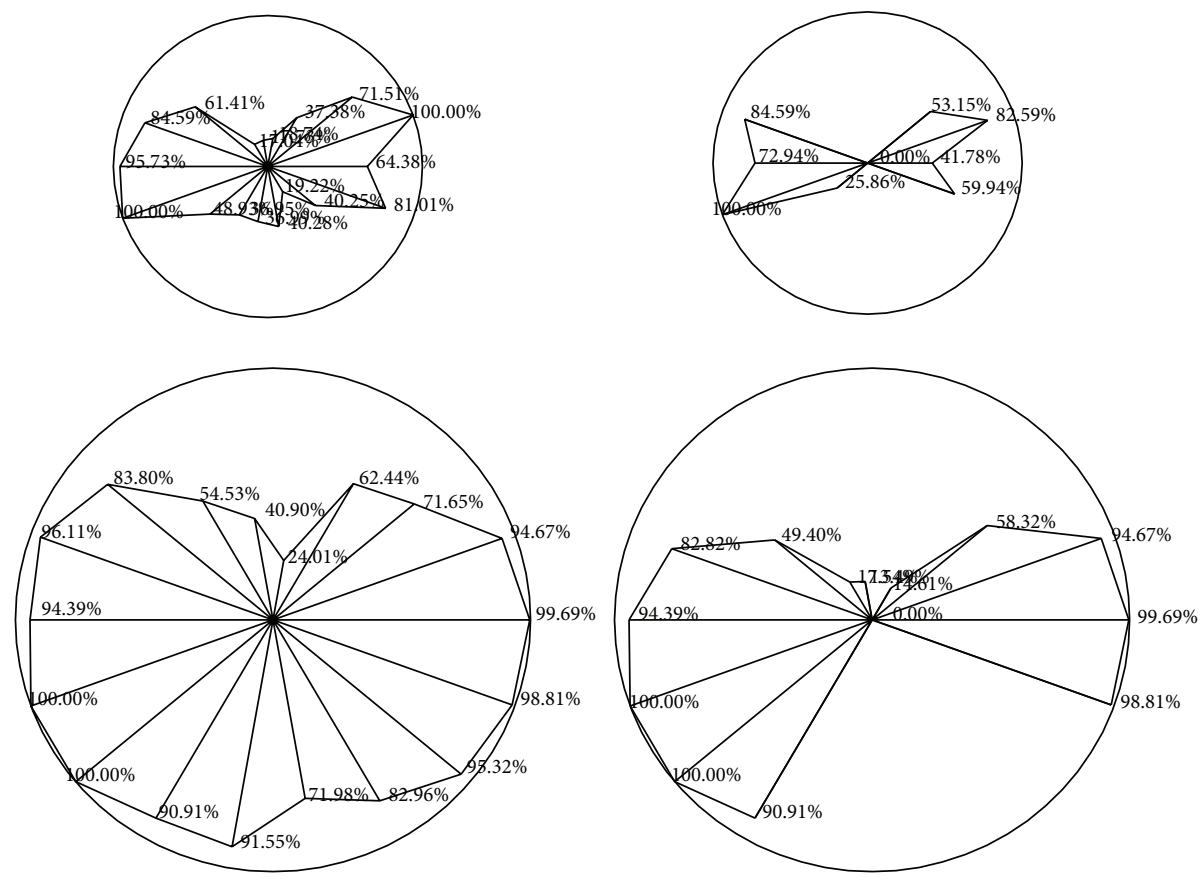

(b) Results of RQD method at different locations

FIGURE 6: RQD map of the dam base controlled by the rock mass discontinuities.

the discontinuities and soft layers is taken into account when building the dam base.

In Figure 5, it is quite clear that there are many soft layers in the rock masses of the dam base, as well as in the soft interlayer distributed throughout the entire dam base zone. Based on the results of the field engineering geological survey, these soft layers showing the shape of the knee buckling are found below the dam base and will lead to detrimental results.

3.3.2. Assessment of Rock Masses Quality. It may be concluded from Figure 5 that two types of superiority discontinuities exist in the rock masses with the exception of the soft layers. In addition, the discontinuities tend to develop better upstream than downstream. In order to reasonably evaluate the rock masses dissected by the discontinuities, a comprehensive method which evaluates the rock masses from all directions must be used.

Table 3 shows the intactness assessment system of rock masses of the dam base. As seen, the RQD in the center of dam base is lower than that in the sides. This indicates that the rock masses in the center of the dam base are broken due to tectonic movement. In addition, the RQD in the tunnel is larger than that in the borehole. This phenomenon is proven by the constructed 3D model in Figure 6.

(1) Evaluation of RQD. The evaluation results of the rock mass quality are shown in Figure 6(a). It may be concluded that the RQD method is arbitrary and is able to evaluate the 


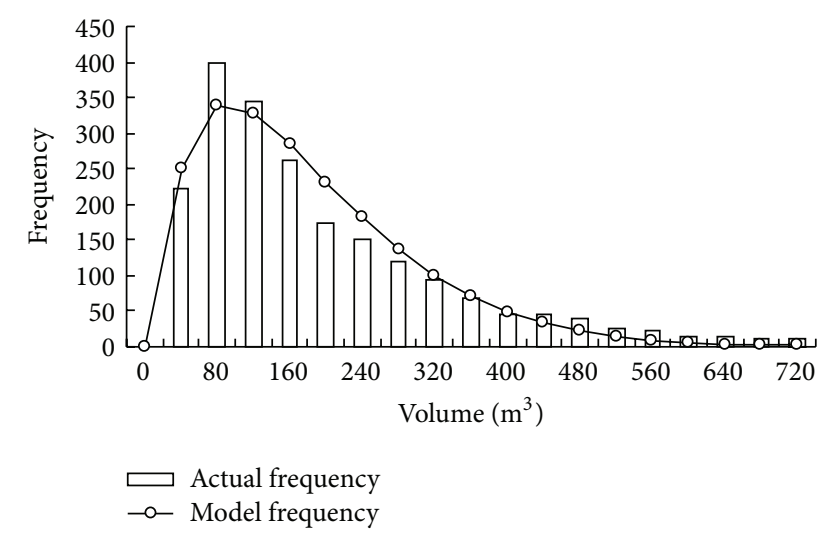

FIgURE 7: Actual and model distribution of the rock block size.

rock mass quality from any direction. Meanwhile, as a typical measurement, the borehole is still used to evaluate the rock mass quality. Vertically below the dam surface, the value of the ROD shown by the borehole is smaller than that above the surface, and the RQD values of all other parts of the dam have little differences among them. When the threshold value is 7.0, the RQD value is typically 0 ; when the threshold value of the RQD is smaller, the RQD value approaches $100 \%$, while the RQD value of the rock masses below the dam remains at about $95 \%$.

Figure 6(b) shows the RQD values under two threshold values, namely, $3.0 \mathrm{~m}$ and $5.0 \mathrm{~m}$, at two different locations. Regardless of where the rock masses are located, the RQD is anisotropic. In the NNE direction the rock mass quality is higher, while in the NNW direction the quality is lower, and while the threshold value is larger, the RQD value tends to be 0 . For the rock masses near the contact surface vertically below the dam base, the RQD value decreases with the threshold value decreasing.

(2) Rock Block Characteristic Analysis. Figure 7 shows the statistics of the rock mass volumes. As seen, the majority of the volume of the rock blocks is less than $300 \mathrm{~m}^{3}$, the lowest rock volume is $6.5 \mathrm{~m}^{3}$, the highest is $5367.8 \mathrm{~m}^{3}$, and the average value is $207.0 \mathrm{~m}^{3}$. The model is consistent with the Weibull distribution, and the model resembles the actual data accurately.

3.3.3. Discontinuous Deformation Analysis. As seen in Figure $8(\mathrm{a})$, in order to analyze the deformation of the dam base rock masses during the service period, the measure points are arranged in the dam base or at locations where the fissures are likely to be produced. Then the horizontal displacement, vertical displacement, horizontal velocity, and vertical velocity are analyzed, and the results are shown in Figures 8(b) to 8(e).

Similar trends with different measure points are seen in both Figures 8(b) and 8(c). The displacement of the forepart of the dam is larger than the ones in the center and rear parts of the dam. In the displacement of point 4 , the measure points in the forepart are larger than those in all the remaining parts, and the highest value is $20 \mathrm{~cm}$. The highest value of displacement in the rear part of the dam ranges from 15 to $17 \mathrm{~cm}$. The base of the dam may be divided into four parts; one of these measure points has the largest displacement, namely, point 4 ; the points $5,6,18,20$, and 25 form the second group, their displacements ranging from 12.5 to $17.5 \mathrm{~cm}$; the third group contains points 7,8 , and 19 , their displacements ranging from 11 to $12.5 \mathrm{~cm}$; and the fourth group contains points 9 , 22 , and 23, the displacements of which are all approximately $10 \mathrm{~cm}$.

As seen in Figure 8(d), the altering regularity of the Xvelocity developed with time ranges between 1.5 and $4.0 \mathrm{~s}$; points 8 and 9 have velocities in the opposite direction as the other points; the curves vary widely beginning from $1.5 \mathrm{~s}$; the maximum velocity value is greater than $4.0 \mathrm{~cm} / \mathrm{s}$; and beginning from $5 \mathrm{~s}$, the trends of every point are similar. As a whole, the range of the forepart of the dam is larger than that of the rear part; the changing regularity of the curves is similar from 1.5 to $5.0 \mathrm{~s}$, with the exception of point 25 , the curve of which is lower than the others. In the end, the respective velocities of all the points tend to zero. The curve of the Yvelocity shown in Figure 8(e) alters regularly, from 0 to $4.5 \mathrm{~s}$; beginning from $4.5 \mathrm{~s}$, the displacements of the points in the dam base begin to change, and the one in the forepart is more evident than that in the rear. The reason for this phenomenon is that the dam deforms toward the rear due to the water pressure, and the rock masses of the forepart are uplifted, resulting in rock mass relaxation.

3.3.4. Failure Analysis of Dam Base. It is convenient to examine the actual damage of the rock masses through the DDA program. The results are calculated via 1000 calculation steps in DDA and are shown in Figure 9, in which the small circles at the top represent the damage degree. The DDA program considers the effects of many groups of discontinuities, and the direction of the discontinuities alters widely due to the knee buckling shape.

According to the overload method used in the DDA program, the rock mass failure of the dam base is classified as tensile fracture damage. The large circles in Figure 9 show that the discontinuities have a relatively large opening, due to the deformation of the dam base. In Figure 10, the curve of the horizontal displacement flattens out as the overload multiples reach 7.0 times, and when the overload multiples range from 7.0 to 7.5 times, the curve of the vertical displacement ceases to change. The main reasons for this phenomenon include the fact that the rock masses of the dam base readjust after being damaged, and the rocks in the rear of the dam act as a resistance. Therefore it may be concluded that the damage of the rock masses of the dam base is simulated very effectively using the DDA method in the service period, and the failures and discontinuities in the contact part of the dam base may be easily observed.

\section{Conclusions}

RQD is one of the most important indexes for assessing the intactness of rock masses which depend on the geometrical characteristics of their discontinuities. In this paper it is 


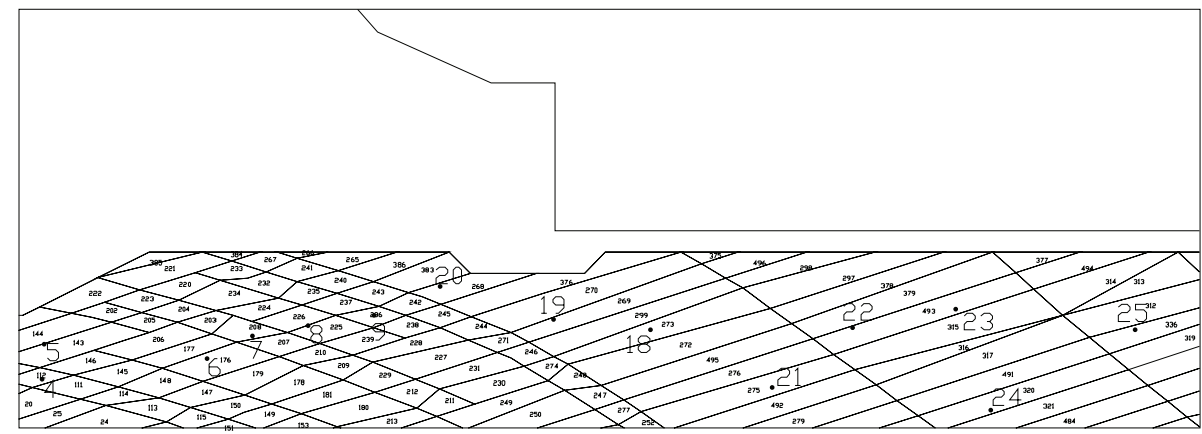

(a) Measure points in the dam base

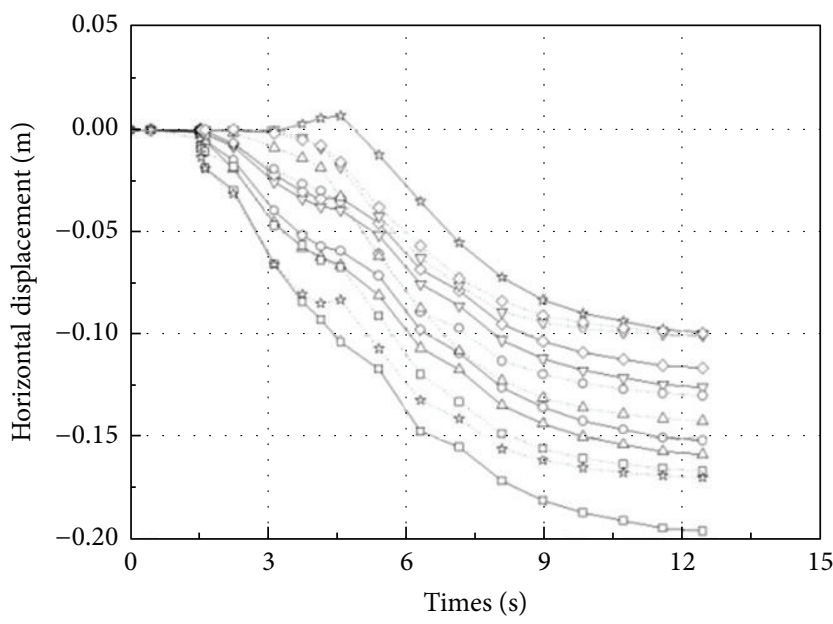

(b) X-displacement with time of measure points

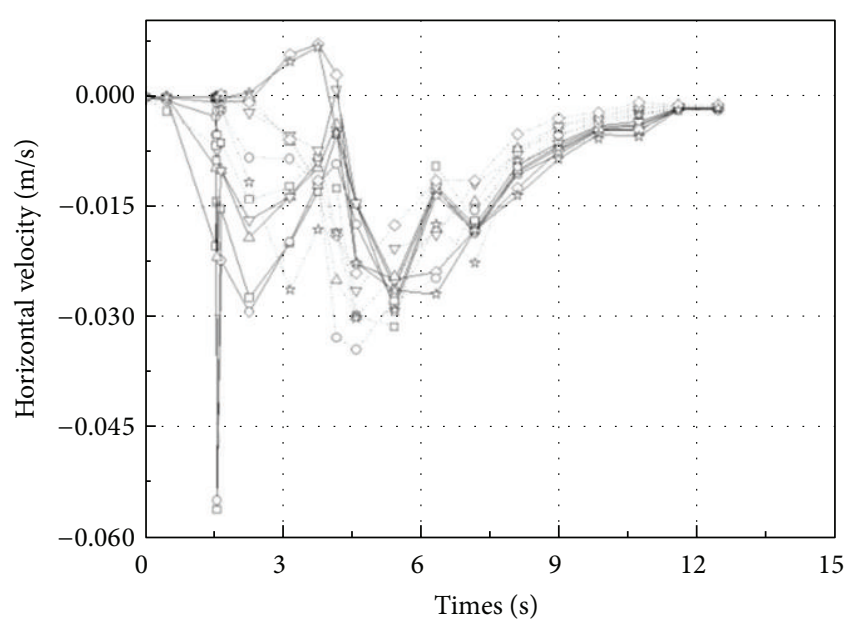

(d) X-velocity with time of measure points

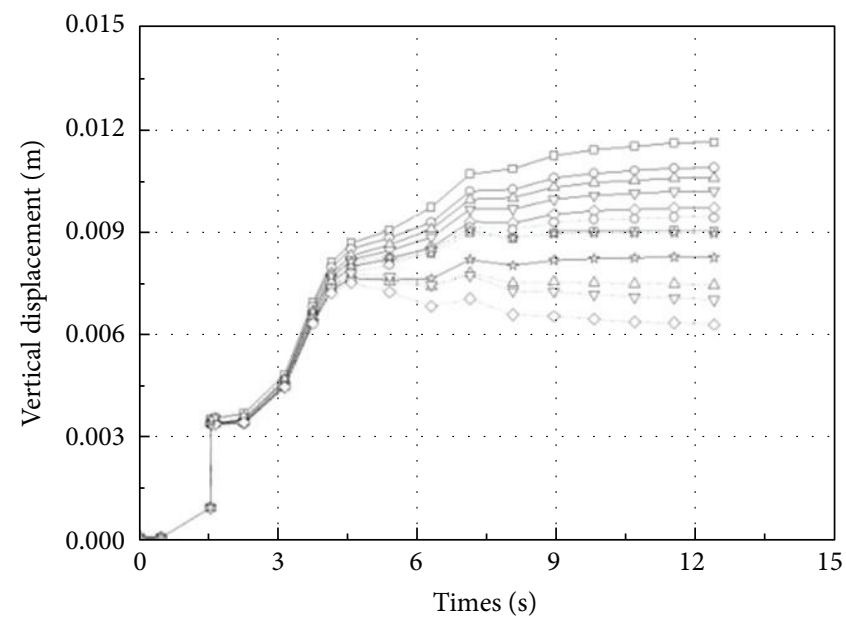

(c) Y-displacement with time of measure point

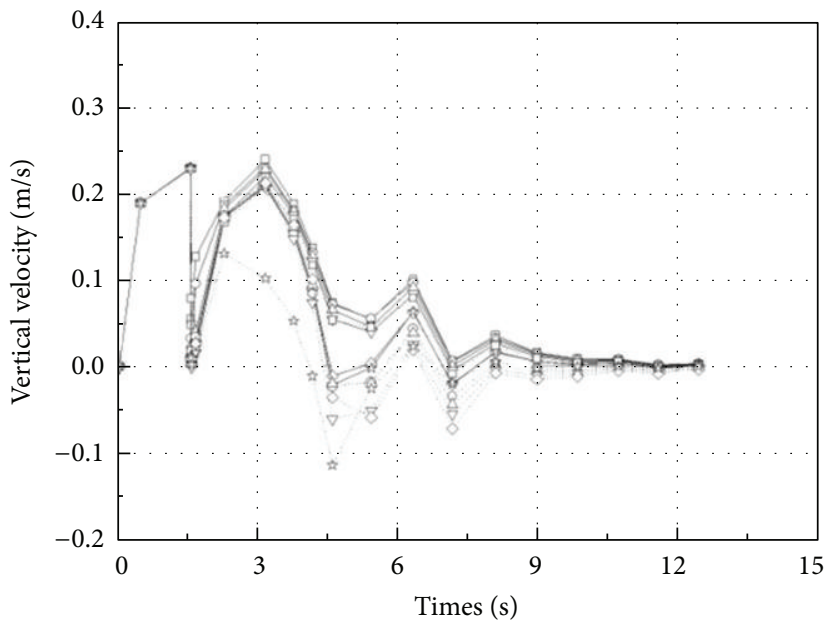

(e) Y-velocity with time of measure points

FIGURE 8: Displacement and velocity with time of different measure points in the dam base.

shown that the use of the optimal RQD threshold value greatly extends the range of RQD values. A series of methods is used to assess rock quality, construct a 3D model, and evaluate the stability of the dam base. The conclusions of the study are as follows.
(1) Based on the mechanism of the geological mechanics, the elliptical discontinuities are used to simulate the rock structure, and this method is applied to the dam base of Xiangjiaba hydropower station. This study shows that the effects of the rock structure are caused 


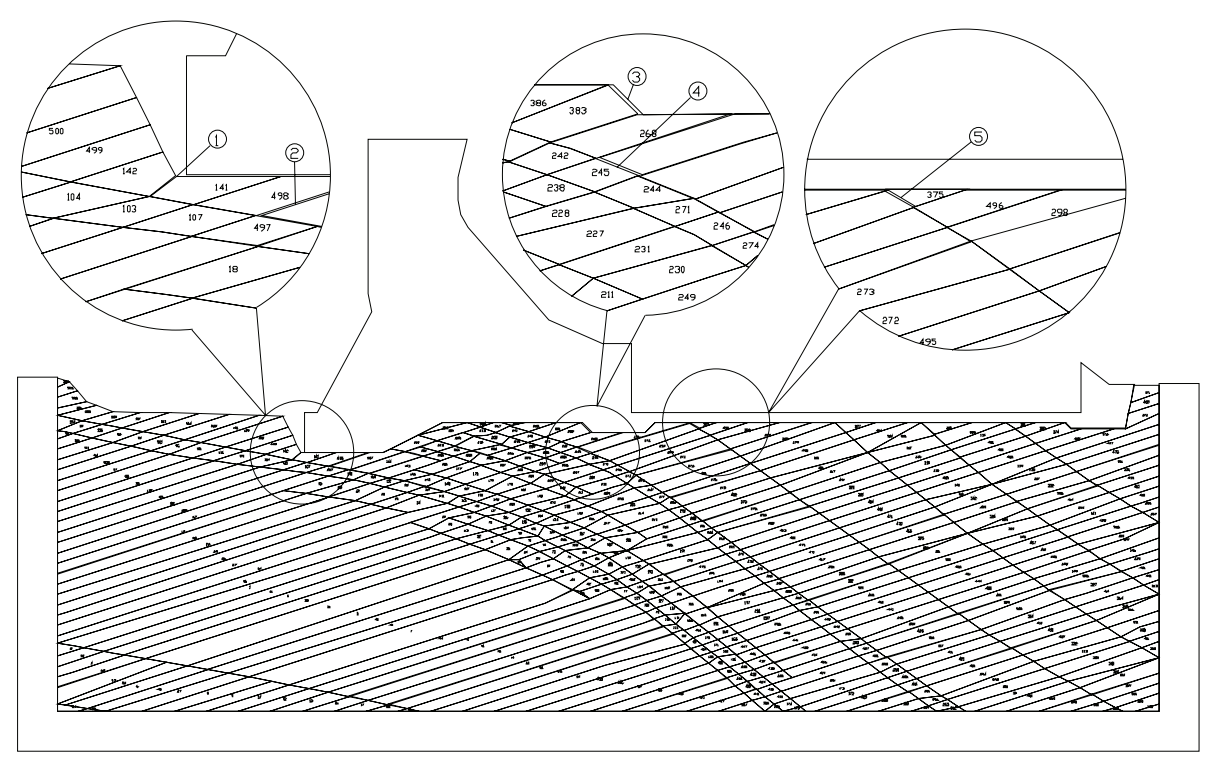

FIGURE 9: Fracture of rock masses in the dam base.

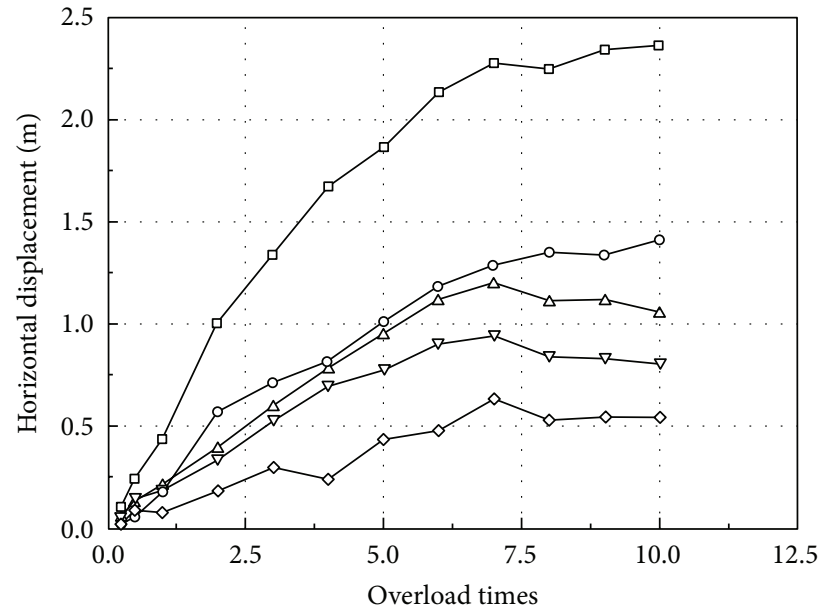

$\begin{array}{ll}\rightarrow-1 & \rightarrow 4 \\ \multimap-2 & \multimap-5 \\ \triangle-3 & \end{array}$

(a) Horizontal displacement with overload times

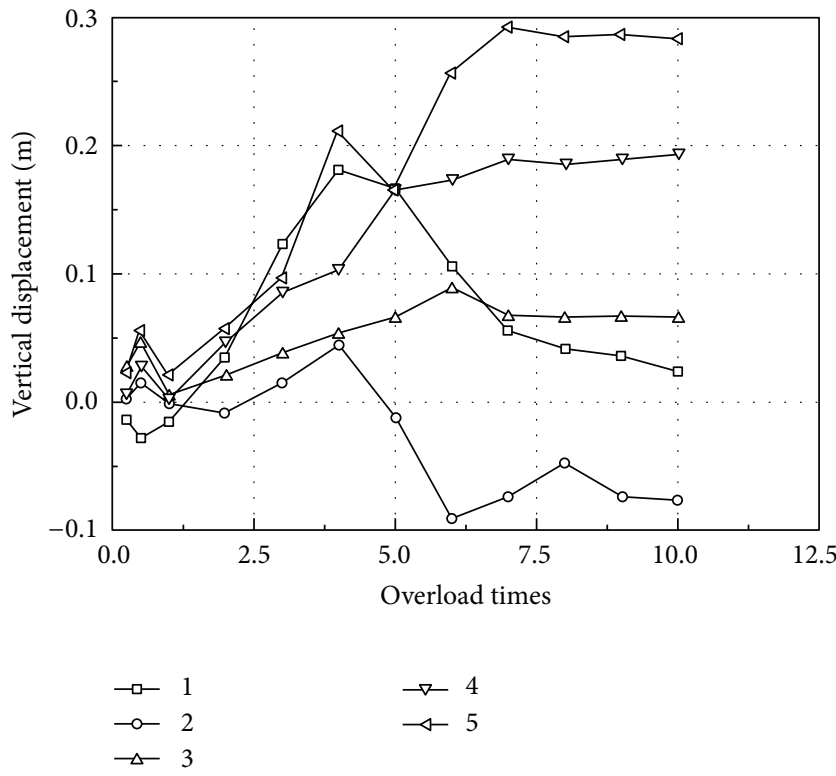

(b) Vertical displacement with overload times

FIGURE 10: Relationship between overload and displacement of the measure points.

by the special discontinuities during the simulation, and this method is very valid for application to the simulation of the rock structure.

(2) Based on the anisotropic characteristic of the rock masses, the modified RQD method with the threshold value and $3 \mathrm{D}$ space is applied to confirm the rationality of the $3 \mathrm{D}$ simulation and evaluate the rock mass quality of the dam base.

(3) Based on the 3D structure of the dam base, the ground profile applied in the discontinuous deformation analysis is obtained by cutting the model and the rock mass quality and the strain characteristic of the dam base are analyzed. The overload method is used to consider the failures occurring near the contact surface of the dam base and the rock masses, and the stability coefficient of the dam is determined through calculation.

\section{Acknowledgments}

This study is financially supported by the Natural Science Foundation of China (Grants nos. 41002089 \& 41102162) and Jiangsu Overseas Research \& Training Program for 
University Prominent Young and Middle-aged Teachers and Presidents. The authors would also like to acknowledge the editors and reviewers of this paper for their very helpful comments and valuable remarks.

\section{References}

[1] D. H. Zhong, M. C. Li, L. G. Song, and G. Wang, "Enhanced NURBS modeling and visualization for large 3D geoengineering applications: an example from the Jinping first-level hydropower engineering project, China," Computers and Geosciences, vol. 32, no. 9, pp. 1270-1282, 2006.

[2] H. H. Zhu, X. Y. Zhuang, Y. C. Cai, and G. Ma, "High rock slope stability analysis using the enriched meshless Shepard and least squares method," International Journal of Computational Methods, vol. 8, no. 2, pp. 209-228, 2011.

[3] L. Jing, "Formulation of discontinuous deformation analysis (DDA) - an implicit discrete element model for block systems," Engineering Geology, vol. 49, no. 3-4, pp. 371-381, 1998.

[4] J. Andersson and B. Dverstorp, "Conditional simulations of fluid flow in three-dimensional networks of discrete fractures," Water Resources Research, vol. 23, no. 10, pp. 1876-1886, 1987.

[5] D. Elsworth, "A hybrid boundary element-finite element analysis procedure for fluid flow simulation in fractured rock masses," International Journal for Numerical and Analytical Methods in Geomechanics, vol. 10, no. 6, pp. 569-584, 1986.

[6] J. C. S. Long, P. Gilmour, and P. A. Witherspoon, "A model for steady fluid flow in random three-dimensional networks of disc-shaped fractures," Water Resources Research, vol. 21, no. 8, pp. 1105-1115, 1985.

[7] L. Smith and F. W. Schwartz, "An analysis of the influence of fracture geometry on mass transport in fractured media," Water Resources Research, vol. 20, no. 9, pp. 1241-1252, 1984.

[8] S. D. Priest and J. A. Hudson, "Discontinuity spacings in rock," International Journal of Rock Mechanics and Mining Sciences and, vol. 13, no. 5, pp. 135-148, 1976.

[9] J. P. Harrison, "Selection of the threshold value in RQD assessments," International Journal of Rock Mechanics and Mining Sciences, vol. 36, no. 5, pp. 673-685, 1999.

[10] Z. Sen and A. Kazi, "Discontinuity spacing and RQD estimates from finite length scanlines," International Journal of Rock Mechanics and Mining Sciences and, vol. 21, no. 4, pp. 203-212, 1984.

[11] Z. Şen, "Theoretical RQD-porosity-conductivity-aperture charts," International Journal of Rock Mechanics and Mining Sciences and Geomechanics, vol. 33, no. 2, pp. 173-177, 1996.

[12] L. Zhang and H. H. Einstein, "Using RQD to estimate the deformation modulus of rock masses," International Journal of Rock Mechanics and Mining Sciences, vol. 41, no. 2, pp. 337-341, 2004.

[13] X. W. Jiang, L. Wan, X. S. Wang, X. Wu, and X. Zhang, "Estimation of rock mass deformation modulus using variations in transmissivity and RQD with depth," International Journal of Rock Mechanics and Mining Sciences, vol. 46, no. 8, pp. 13701377, 2009.

[14] D. Milne, J. Hadjigeorgiou, and R. Pakalnis, "Rock mass characterization for underground hard rock mines," Tunnelling and Underground Space Technology, vol. 13, no. 4, pp. 383-391, 1998.

[15] D. T. Snow, "Rock fracture spacings, openings, and porosities," Journal of the Soil Mechanics and Foundations Division, vol. 94, no. 1, pp. 73-91, 1968.
[16] G. H. Shi and R. E. Goodman, "Two dimensional discontinuous deformation analysis," International Journal for Numerical and Analytical Methods in Geomechanics, vol. 9, no. 6, pp. 541-556, 1985.

[17] G. H. Shi, "Three dimensional discontinuous deformation analysis," in Rock Mechanics in the National Interest: Proceedings of the 38th U.S. Rock Mechanics Symposium, pp. 1421-1428, A.A. Balkema, Rotterdam, The Netherlands, 2001.

[18] Q. H. Jiang and M. R. Yeung, "A model of point-to-face contact for three-dimensional discontinuous deformation analysis," Rock Mechanics and Rock Engineering, vol. 37, no. 2, pp. 95-116, 2004.

[19] M. R. Yeung, Q. H. Jiang, and N. Sun, "Validation of block theory and three-dimensional discontinuous deformation analysis as wedge stability analysis methods," International Journal of Rock Mechanics and Mining Sciences, vol. 40, no. 2, pp. 265-275, 2003.

[20] Y. H. Hatzor and A. Feintuch, "The validity of dynamic block displacement prediction using DDA," International Journal of Rock Mechanics and Mining Sciences, vol. 38, no. 4, pp. 599-606, 2001.

[21] M. M. MacLaughlin and E. A. Berger, "A decade of DDA validation: development and application of discontinuous modeling for rock engineering," in Proceedings of the 6th International Conference on Analysis of Discontinuous Deformation, pp. 13-31, A.A. Balkema, Rotterdam, The Netherlands, 2003.

[22] D. M. Doolin and N. Sitar, "Displacement accuracy of discounting deformation analysis method applied to sliding block," Journal of Engineering Mechanics, vol. 128, no. 11, pp. 1158-1168, 2002.

[23] M. Tsesarsky, Y. H. Hatzor, and N. Sitar, "Dynamic displacement of a block on an tnclined plane: analytical, experimental and DDA results," Rock Mechanics and Rock Engineering, vol. 38, no. 2, pp. 153-167, 2005.

[24] Y. H. Hatzor, A. A. Arzi, Y. Zaslavsky, and A. Shapira, "Dynamic stability analysis of jointed rock slopes using the DDA method: King Herod's Palace, Masada, Israel," International Journal of Rock Mechanics and Mining Sciences, vol. 41, no. 5, pp. 813-832, 2004.

[25] N. Sitar, M. M. MacLaughlin, and D. M. Doolin, "Influence of kinematics on landslide mobility and failure mode," Journal of Geotechnical and Geoenvironmental Engineering, vol. 131, no. 6, pp. 716-728, 2005.

[26] Y. I. Kim, B. Amadei, and E. Pan, "Modeling the effect of water, excavation sequence and rock reinforcement with discontinuous deformation analysis," International Journal of Rock Mechanics and Mining Sciences, vol. 36, no. 7, pp. 949-970, 1999.

[27] J. H. Wu, Y. Ohnishi, and S. Nishiyama, "Simulation of the mechanical behavior of inclined jointed rock masses during tunnel construction using discontinuous deformation analysis (DDA)," International Journal of Rock Mechanics and Mining Sciences, vol. 41, no. 5, pp. 731-743, 2004.

[28] M. Tsesarsky and Y. H. Hatzor, "Tunnel roof deflection in blocky rock masses as a function of joint spacing and frictiona parametric study using discontinuous deformation analysis (DDA)," Tunnelling and Underground Space Technology, vol. 21, no. 1, pp. 29-45, 2006. 


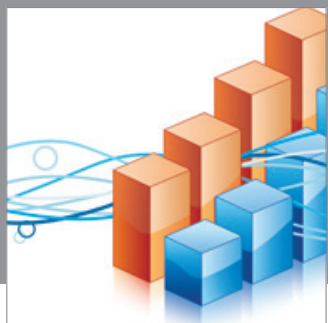

Advances in

Operations Research

mansans

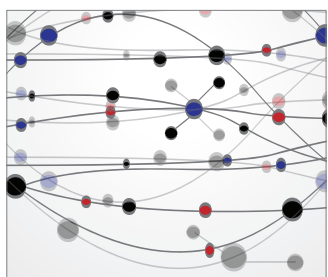

The Scientific World Journal
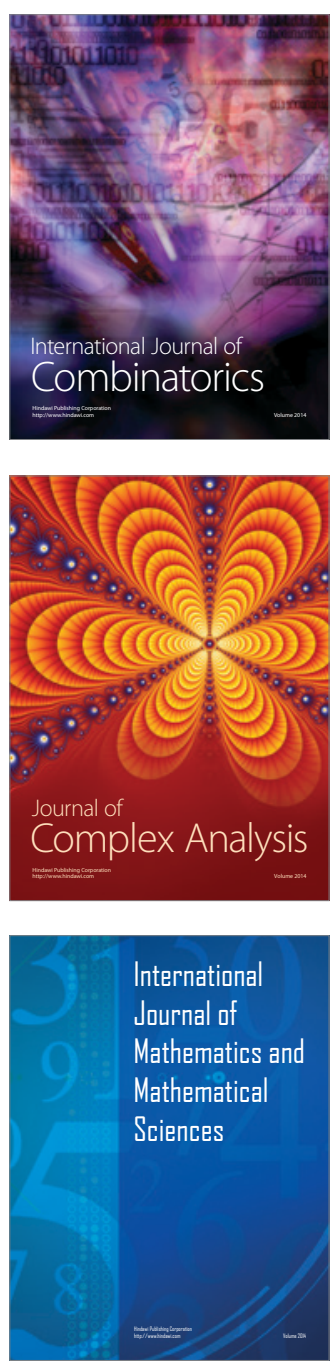
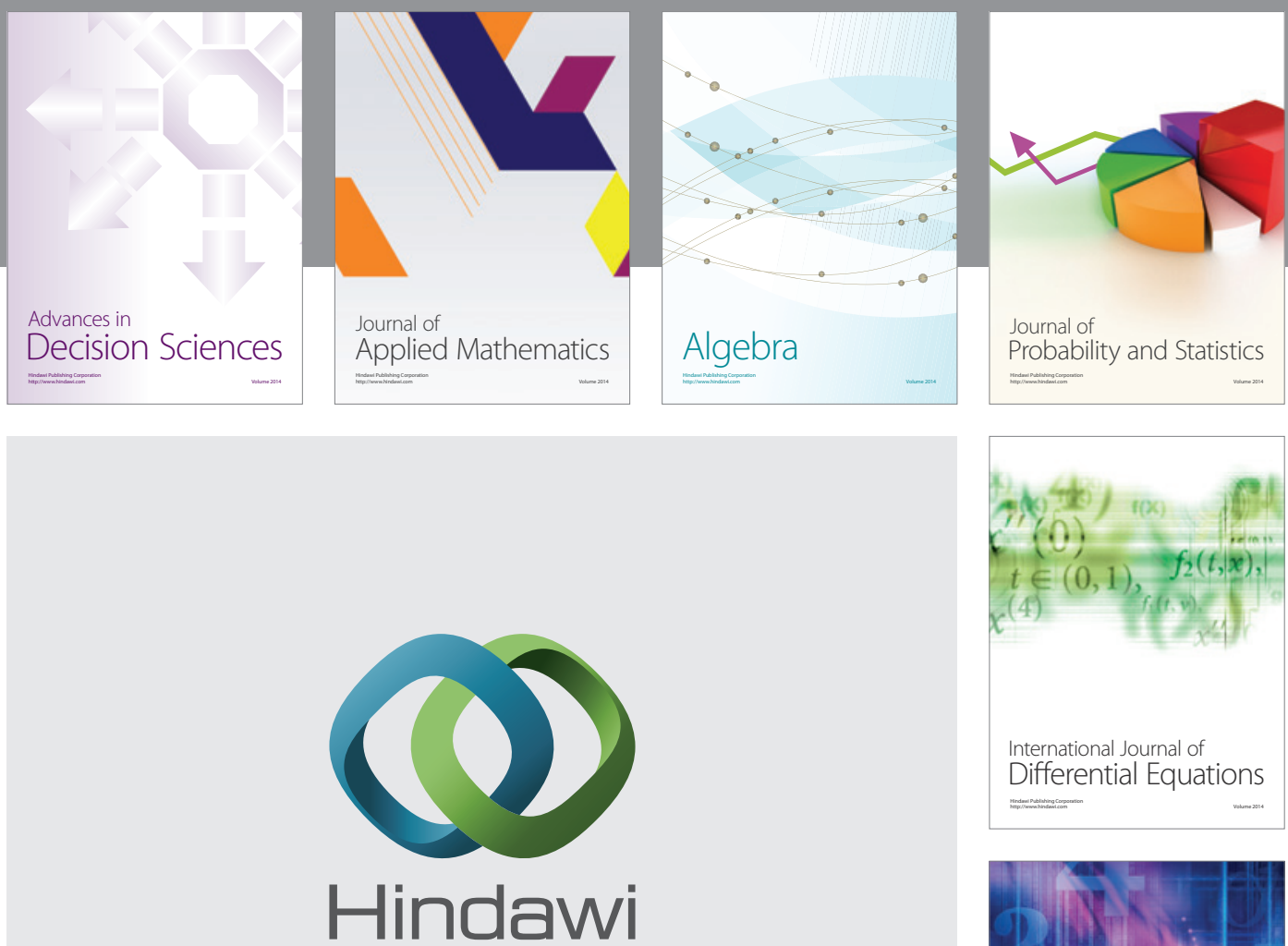

Submit your manuscripts at http://www.hindawi.com
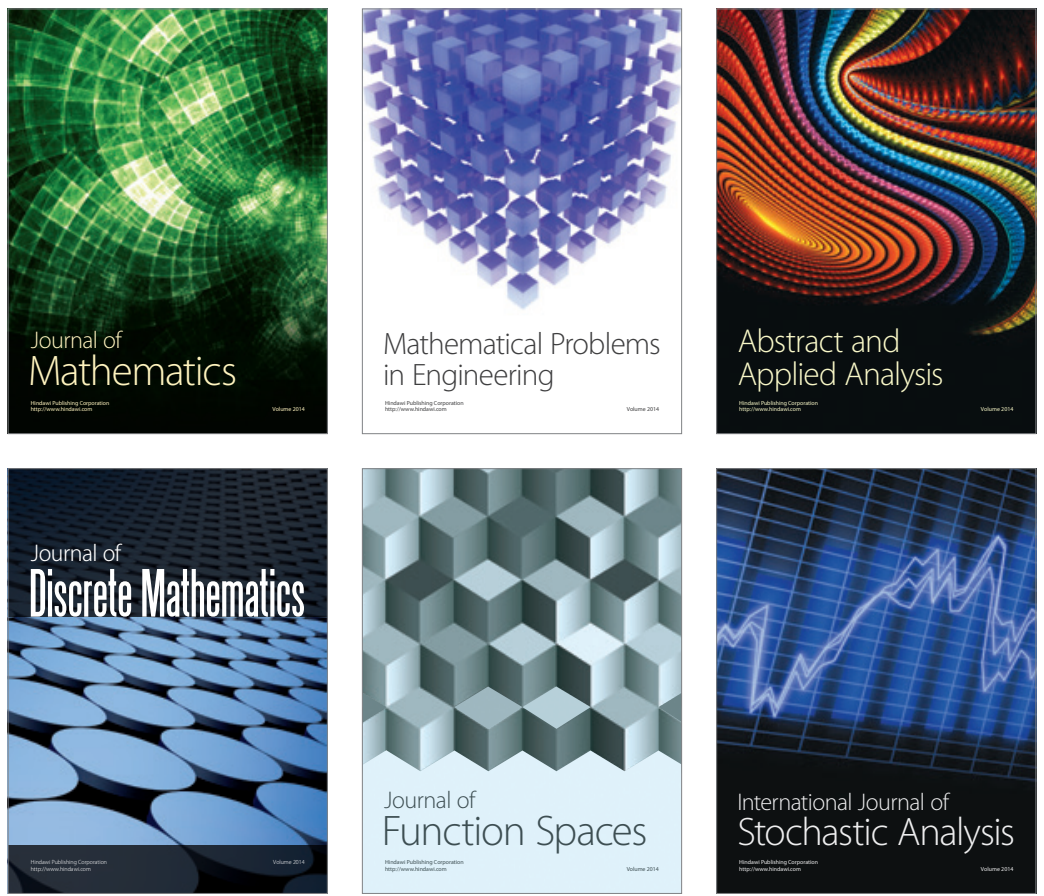

Journal of

Function Spaces

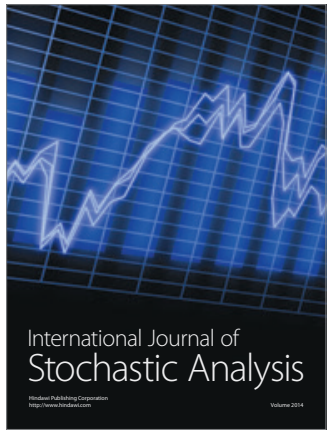

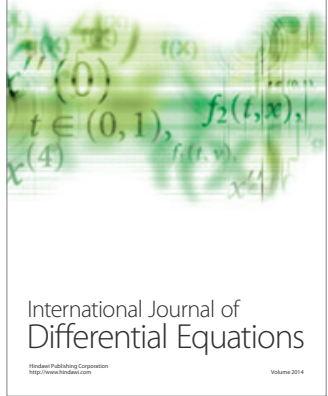
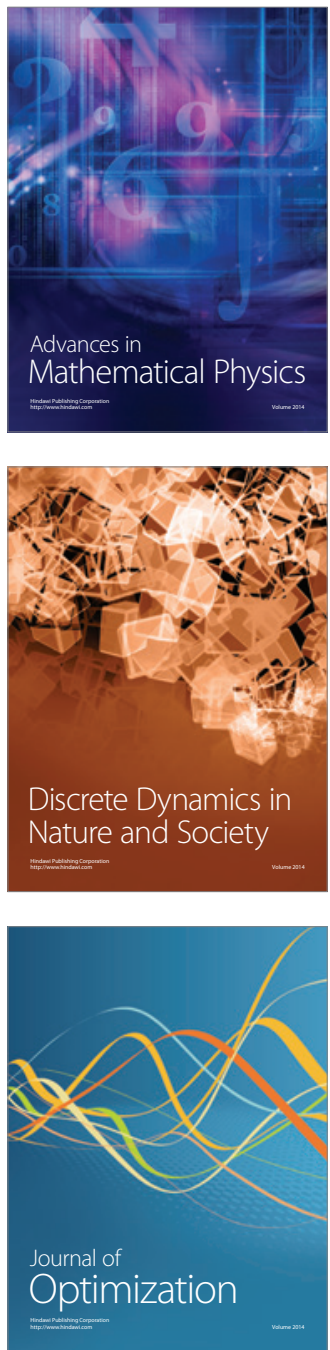